\title{
O uso de mapas conceituais para leitura de textos filosóficos em sala de aula no Ensino Médio
}

\author{
Ademir Aparecido Pinhelli Mendes ${ }^{14}$ \\ Edson Teixeira de Rezende ${ }^{15}$
}

\begin{abstract}
Resumo
$\mathrm{O}$ artigo apresenta os resultados de uma investigação de abordagem qualitativa realizada a partir de uma experiência de aprendizagem filosófica desenvolvida com estudantes do $3^{\circ}$ ano do Ensino Médio em duas Escolas Públicas do Estado do Paraná. Parte da seguinte problemática: em que medida o uso do mapa conceitual pode ser utilizado como ferramenta pedagógica para a leitura, análise e compreensão de textos filosóficos no Ensino Médio? A investigação mostra estratégias e possibilidades do uso do mapa em sala e os impactos que ocorrem na aprendizagem filosófica dos estudantes. As cartas e os mapas conceituais produzidos pelos educandos sobre o tema política - a partir do capítulo XVII d'O Príncipe de Maquiavel -, mostram tanto a presença de elementos da vida cotidiana como apropriações conceituais e reflexões evidenciando a aprendizagem filosófica.
\end{abstract}

Palavras-chave: filosofia; aprendizagem; mapa conceitual; mediação didática.

\section{The use of concept maps for reading philosophical texts in high school classes}

\begin{abstract}
This article presents the results of an investigation by conducting a qualitative research from philosophical learning experience developed with students of third year of High School in two public schools in the State of Paraná. The main issue is: to what extent the use of the concept map can be used as a pedagogical tool for reading, analysis and understanding philosophical texts in High School? The investigation shows strategies and possibilities of the use of the map in classroom and the impacts that occur on philosophical learning by the students. The letters and concept maps produced by the students on the topic Politics - from chapter XVII of The Prince by Machiavelli - show either the presence of elements of everyday life and conceptual appropriations and reflections evidencing philosophical learning.
\end{abstract}

Keywords: philosophy; Learning; concept map; didactic mediation.

\footnotetext{
${ }^{14}$ Mestre em Educação (UFPR). Professor de Filosofia da Rede Estadual de Educação do Paraná. E-mail: pinhellimendes@hotmail.com

${ }^{15}$ Mestre em Educação (UFPR). Professor de Filosofia da Rede Estadual de Educação do Paraná. E-mail: etrezende@ig.com.br
} 


\section{Introdução}

A Lei $n^{\circ} 11.684$, de 2 de junho de 2008, alterou o Art. 36 da LDB n 9394/96 e tornou obrigatórias a oferta da Filosofia e da Sociologia no Ensino Médio, inaugurando uma nova etapa na discussão sobre o lugar da filosofia no currículo escolar. O propósito deste texto é contribuir com essa discussão ao explicitar os resultados de uma pesquisa-ação realizada no âmbito do ensino da filosofia com estudantes da $3^{\text {a }}$ série de Ensino Médio. Ao utilizar o Mapa Conceitual como mediação pedagógica para a leitura de textos filosóficos e estudo dos conceitos de Filosofia Política, presentes no capítulo XVII da obra O Príncipe de Maquiavel, analisamos o processo de aprendizagem significativa no ensino da filosofia no ensino médio.

O percurso realizado nessa pesquisa mostra que o ensino da Filosofia com educandos do Ensino Médio, na perspectiva de uma educação emancipadora, necessita apropriar-se de metodologias que lhes assegurem as condições de "aprendizagem" dos conceitos filosóficos, como condição para a reflexão da existência e reconhecimento do ser no mundo. Entendemos a aprendizagem como sendo o processo pelo qual os educandos investigam e se apropriam dos conceitos filosóficos ressignificando-se para compreender sua vida cotidiana. Utilizandose do recurso de intervenção didática para a produção de mapas conceituais e aprendizagem significativa, proposto por Ausbel (1982), os educandos estudaram o conteúdo da Filosofia Política com um recorte no capítulo XVII do Príncipe de Maquiavel. O mapa conceitual é uma expressão gráfica do conhecimento realizada por meio de proposições relacionadas entre si. Os mapas conceituais produzidos pelos educandos permitem observar elementos da vida cotidiana presentes nas proposições por eles elaboradas.

Para análise teórica dos materiais empíricos produzidos na pesquisa-ação, apropriamo-nos de autores reconhecidos no campo das pesquisas no ensino de Filosofia no Ensino Médio e que nos oferecem coerência epistemológica com os objetivos da pesquisa. De Horn (2008) emprestamos o conceito de mediação praxiológica dos conteúdos, que se constitui no conjunto de elementos didáticos do qual fazem parte o conteúdo selecionado, as estratégias de ensino e avaliação, o texto clássico, as novas tecnologias educacionais, o plano de aula, a concepção de filosofia e seu ensino do professor, etc. Severino (2008), ao tratar a importância da Filosofia na formação do adolescente do Ensino Médio, chama atenção para da mediação pedagógica no processo de ensino e aprendizagem da Filosofia. O que, de alguma forma, indica alguns princípios da didática da Filosofia, caracterizada pela historicidade do conhecimento filosófico, pela experiência coletiva do filosofar, pelo rigor metodológico, pelo processo de pesquisa como mediação para construção do pensar, expresso na oralidade e na escrita.

Apropriamo-nos do conceito de vida cotidiana de Agnes Heller (1989), para a qual, "a vida cotidiana é a vida de todo homem" ao "mesmo tempo particular e genérico" e utilizando o mapa conceitual no ensino da filosofia, intencionamos que os educandos problematizem questões da Filosofia Política presentes no seu cotidiano, em seu aspecto micro e macro 
econômico, partindo da referência da obra O Príncipe de Maquiavel. Os resultados da pesquisa são ainda preliminares e a eles chegamos ao analisar as proposições iniciais, produzidas pelos educandos, comparando com as proposições produzidas por eles após o processo de estudo e discussão do texto de Maquiavel, sistematizado nos mapas conceituais. Tais resultados nos permitem afirmar a possibilidade da aprendizagem filosófica, desde que atendidas algumas exigências das mediações praxiológicas e pedagógicas para o ensino da Filosofia.

\section{Mediação praxiológica e a didática da filosofia}

Partindo do pressuposto contido no documento das Diretrizes Orientadoras do Ensino de Filosofia do Estado do Paraná ${ }^{16}$, ao estabelecer que uma das especificidades da Filosofia como disciplina escolar é realizar o trabalho pedagógico com os conceitos filosóficos e, considerando que o processo de aprendizagem ocorre mediado praxiológicamente ${ }^{17}$, nos interessou investigar e analisar o processo pelo qual os estudantes do ensino médio aprendem por meio do trabalho com conceitos filosóficos, de forma sistemática e orientada em sala de aula de Filosofia.

$\mathrm{Na}$ tentativa de dar uma resposta plausível ao problema do ensino da Filosofia, Horn (2008) criou o conceito de mediação praxiológica para indicar a necessidade de empregar uma metodologia específica para o ensino da Filosofia como saber escolar a ser ensinado.

Trata-se, na verdade, de enfatizar a necessidade de repensar o saber a ser ensinado na perspectiva da invenção de um espaço curricular próprio e da indicação de uma perspectiva de organização do saber filosófico para o Ensino Médio; de apontar para a prática de ensinar Filosofia no que se refere à relação entre o conteúdo, os objetivos e a maneira com se ensina (HORN, 2008, p. 181).

Por mediação praxiológica, Horn (2002) compreende o que se constitui como conjunto de mediações didáticas da qual fazem parte o conteúdo selecionado, as estratégias de ensino e avaliação, o texto clássico, as novas tecnologias educacionais, o plano de aula, a concepção de filosofia e seu ensino, que o docente acumula durante seu processo de formação e atuação profissional, etc. Estes instrumentos se constituem como mediação praxiológica, uma vez que não são utilizadas aleatoriamente, mas suas escolhas decorrem da prática social do professor e de como ele compreende a própria natureza do processo educacional, da própria filosofia e seu ensino.

Severino (2008), ao tratar da importância da Filosofia na formação do adolescente do

\footnotetext{
${ }^{16}$ Documento destinado a orientar os professores de Filosofia do ensino médio das escolas públicas estaduais do Estado do Paraná na elaboração da Proposta Pedagógica Curricular.

${ }^{17}$ Conceito criado Horn (2002) para analisar como o professor de Filosofia organiza o currículo escolar da disciplina de Filosofia no Ensino Médio.
} 
ensino médio, chama atenção para a importância da mediação pedagógica no processo de ensino e aprendizagem da Filosofia. O que, de alguma forma, indica alguns princípios da didática da Filosofia, caracterizada pela historicidade do conhecimento filosófico, pela experiência coletiva do filosofar, pelo rigor metodológico, pelo processo de pesquisa como mediação para construção do pensar, dito e escrito. O conjunto de mediações pedagógicas, compreendidas aqui como praxiológicas, constituem uma didática específica do ensino da filosofia, uma vez que surge da prática social do professor, que faz suas escolhas teóricometodológicas tendo em vista uma intencionalidade.

A didática pode ser entendida com a práxis pedagógica do professor, mas, também, como sendo uma disciplina da pedagogia. Segundo Libâneo (2005, p. 143), a didática como disciplina apresenta distinções e adjetivos, dependendo da intencionalidade e finalidade do objeto de ensino e aprendizagem, sendo possível falar em didática fundamental, didática crítico-social, didática histórico-social, etc. Isso nos leva a pensar numa didática específica para cada disciplina, uma vez que cada área de conhecimento tem especificidades quanto ao conteúdo a ser ensinado, o que exige abordagens pedagógicas diferenciadas.

Para Wuench (2007, p.84), reivindicar uma didática da Filosofia é falar em pedagogia filosófica, o modo pelo qual somos apresentados às filosofias e aos filósofos, em que somos, em alguma medida, convidados a filosofar com eles. A dimensão pedagógica da Filosofia indica que existem certos modos de transmissão, já condicionados pela própria formação, ou pela profissionalização da Filosofia. Para além dos procedimentos metodológicos, o aprendizado da Filosofia supõe uma relação pedagógica entre mestre-discípulo. Embora, talvez, nunca tenha existido um mestre da Filosofia, aquela figura do filósofo culturalmente completo, o aprendizado da Filosofia supõe o discipulado, cujo mestre filósofo é o pedagogo a conduzir o discípulo pelo questionamento como caminho, pela procura como método e pela Filosofia como resposta. Em síntese, de acordo com a autora, "a Didática da Filosofia se constitui, como um campo de investigação das questões relacionadas com o ensino e a aprendizagem filosóficas, e com a divulgação, os usos e aplicações da Filosofia em outros contextos" (Idem, p. 86).

A Didática da Filosofia seria constituída de uma parte técnica que exige do professor o domínio do conteúdo, dos métodos e técnicas de ensino da Filosofia e também uma parte existencial, que envolve a relação pedagógica professor-aluno, mestre-discípulo, como condição para filosofar.

\section{Pesquisa-ação e o ensino de filosofia}

Para compreender o processo de ensino e aprendizagem da Filosofia no ensino médio, precisamos ir à escola, à sala de aula e investigar as complexas relações que ocorrem entre os próprios sujeitos do processo de ensino e aprendizagem e, entre os sujeitos e a cultura, as estruturas, etc. É neste contexto que buscamos a resposta para a insistente questão: como 
ensinar Filosofia no ensino médio?

Em busca de uma metodologia para o ensino da filosofia que, ao mesmo tempo fugisse às iniciativas já bem conhecidas pelos manuais didáticos, não engessasse o processo de ensino e aprendizagem e levasse ao risco de tornar não filosófico o ensino da filosofia, demos início a um processo de investigação que se constitui como pesquisa-ação.

A pesquisa-ação é um tipo de pesquisa participante engajada, em oposição à pesquisa tradicional, que é considerada como "independente", "não-reativa" e “objetiva”. Como o próprio nome já diz, a pesquisa-ação procura unir a pesquisa à ação ou prática, isto é, desenvolver o conhecimento e a compreensão como parte da prática. É, portanto, uma maneira de se fazer pesquisa em situações em que também se é uma pessoa da prática e se deseja melhorar a compreensão desta. (ENGEL, 2000, p. 181).

A escolha desta perspectiva metodológica está diretamente ligada à natureza do objeto investigado: aprendizagem de conteúdos/conceitos filosóficos a partir da prática/exercícios dirigidos realizados pelos estudantes com os professores de modo participativo e interativo, ambos na condição de sujeitos da aprendizagem e pesquisadores da sua própria ação epistêmica. O acompanhamento e diálogo dos professores com os estudantes durante a leitura do texto de Maquiavel, a discussão e a elaboração de mapas conceituais permitiu coletar dados empíricos para uma análise mais acurada dos efeitos na aprendizagem do uso do mapa como ferramenta para compreensão do texto filosófico. Por vezes, foi necessário redimensionar o plano de trabalho inicialmente delineado. Portanto, a opção assumida decorreu da própria ação docente dos pesquisadores, que compreendem sua ação em sala de aula como prática problematizadora, ao procurar assumir um posicionamento profissional investigativo do processo de ensino e aprendizagem da filosofia no ensino médio.

O objetivo específico da pesquisa foi realizar um processo de intervenção em sala de aula ao propor aos estudantes a utilização do Mapa Conceitual como uma mediação pedagógica, proposta por Novak (1981) para realizar o processo de ensino e avaliação qualitativa da aprendizagem filosófica com os alunos da disciplina de Filosofia no Ensino Médio.

[...] o mapa conceitual possibilita a representação gráfica do processo de aprendizagem dos conceitos. O mapa conceitual é uma estrutura esquemática para representar um conjunto de conceitos imersos numa rede de proposições. Ele é considerado como um estruturador do conhecimento, na medida em que permite mostrar como o conhecimento sobre determinado assunto está organizado na estrutura cognitiva de seu autor, que assim pode visualizar e analisar a sua profundidade e a extensão. Ele pode ser entendido como uma representação visual utilizada para partilhar significados, pois explicita como o autor entende as relações entre os conceitos enunciados. O mapa conceitual se apoia fortemente na teoria da aprendizagem significativa de David Ausubel, que menciona que o ser humano organiza o seu conhecimento através de uma hierarquização dos conceitos. (TAVARES, 2007, p. X).

Espera-se que, por meio do uso desta mediação pedagógica, os alunos produzam 
evidências empíricas e teóricas, possibilitando aos pesquisadores a análise do processo de ensino e aprendizagem em Filosofia. Para isso, foi realizada uma experiência de ensino com educandos da $3^{\text {a }}$ série do ensino médio ${ }^{18}$. Os alunos estudaram o conteúdo da Filosofia Política, com um recorte no capítulo XVII d'O Príncipe de Maquiavel. Utilizando-se do recurso de intervenção didática para a produção de mapas conceituais e aprendizagem, significativa, proposto por Ausubel (1982).

Os objetivos estabelecidos para a realização da atividade pedagógica foram: a) representar por meio do mapa conceitual os principais conceitos presente no capítulo XVII do Príncipe, escrito por Maquiavel; b) compreender o texto clássico de filosofia utilizando o mapa conceitual como instrumento metodológico para a leitura e compreensão dos conceitos filosóficos; c) compreender os conceitos de política, poder e características do governante em Nicolau Maquiavel; d) analisar os conceitos do florentino com elementos da micro política à macro política atual.

O trabalho com o texto clássico de filosofia exige uso de mediações didáticopedagógicas, a fim de que ocorra uma aprendizagem significativa dos conceitos filosóficos. Entendemos que o uso do mapa conceitual permite que o texto seja lido, compreendido e apropriado pelos alunos do ensino médio. Para Moreira (2010, p. 77), os mapas conceituais constituem uma estratégia facilitadora da aprendizagem significativa e da conceitualização. $O$ trabalho com esta técnica permite focar a aprendizagem de conceitos, mas, para isso, é importante que sejam construídos colaborativamente pelos alunos sob a mediação do professor. É no processo de construção coletiva que os alunos poderão discutir a relevância dos conceitos que devem ser incluídos no mapa e como devem ser ordenados. Neste processo, devem discutir também quais termos de ligação são relevantes para realizar a conexão dos conceitos.

O processo de leitura do texto filosófico, por meio da produção e discussão dos mapas conceituais, tanto no plano individual como no coletivo, mediado pelo trabalho docente, constitui-se na produção de materiais empíricos, a partir dos quais é possível avaliar qualitativamente o processo de ensino e aprendizagem, por meio do qual os alunos se apropriam e ressignificam os conceitos filosóficos. Neste processo, os alunos começam a perceber que os conceitos são elementos importantes na construção do conhecimento filosófico. Assim, os materiais produzidos são tomados como um conjunto de documentos que acabam por constituir um dossiê do processo de aprendizagem.

Compreendemos que o dossiê de aprendizagem filosófica é um instrumento que facilita a coleta e organização das produções escritas pelos estudantes. Sua finalidade é possibilitar a análise do processo de aprendizagem, identificando avanços e dificuldades. É uma coletânea das atividades produzidas pelos estudantes, ao longo de um determinado período de tempo, a fim possibilitar a análise ampla e detalhada dos diferentes momentos e

\footnotetext{
${ }^{18}$ A pesquisa foi realizada em duas escolas públicas de ensino médio localizadas em Curitiba e Região Metropolitana.
} 
elementos do seu processo de aprendizagem.

\section{Ambiente de aprendizagem filosófica significativa}

Partindo da tese Aristotélica, segundo a qual o "homem é naturalmente um animal político destinado a viver em sociedade" (Aristóteles, 2001, p. 15), problematizamos que somos seres políticos e indagamos: que características identificam o ser humano como tal? E, como a macro política se incorpora nas características do sujeito político?

$\mathrm{Na}$ perspectiva de investigarmos essas indagações, um autor como Nicolau Maquiavel, auxilia a provocar uma reflexão com os educandos já que quando indagados sobre o que é a política, geralmente identificam “corrupção, mentiras, busca por status, interesses próprios, dentre outros conceitos depreciativos" como sendo conceitos centrais para explicar a política.

Esses elementos são evidenciados em sala de aula por meio do mapa conceitual, ferramenta que se utiliza de conceitos. Aqui, tomamos o cuidado com o apontamento de Aristóteles (2005, p. 39), "as coisas têm apenas um nome em comum e a definição de essência correspondente ao nome é diferente".

Aristóteles ressalta a importância do cuidado com o conceito para expressar a ideia "coisa", o elemento e, quando relacionados entre si, os conceitos devem apresentar sentenças que são "afirmativas ou negativas, tem de ser verdadeiras ou falsas" (ibidem, p. 42). Essas são reconhecidas quando "dotada de significação, sendo que esta ou aquela sua parte, pode ter um significado particular de alguma coisa, ou seja, que é enunciado" (ibidem, p. 84). O que faz com que essa sentença possa ser reconhecida como proposição? São "as que encerram verdade ou falsidade em si mesma" (idem).

O primeiro momento do trabalho de pesquisa teve início com a exibição aos alunos de vídeos tutoriais, demonstrando o processo de construção de mapas conceituais com o objetivo de aprender como podem ser construídos. Por isso, foram exibidos dois vídeos: o primeiro demonstrando como realizar a instalação do Programa Cmap Tools ${ }^{19}$. O segundo demonstrando o processo de construção do mesmo no Programa Cmap Tools ${ }^{20}$.

Como forma de exercitar a construção de mapas conceituais, os alunos identificaram 10 conceitos para explicar o que é política e construir um mapa conceitual, utilizando os conceitos identificados. Após produzir o mapa conceitual, os alunos produziram um texto com no mínimo dez linhas, explicando os conceitos utilizados no mapa conceitual e explicitando sua compreensão sobre a política. Em seguida, os textos foram lidos e discutidos em sala sob a mediação do professor.

O segundo momento da metodologia, utilizada para realização da pesquisa, consistiuse na exibição de documentário ${ }^{21}$ sobre Nicolau Maquiavel ressaltando aspectos da vida e

\footnotetext{
${ }^{19}$ Vídeo disponível em: http://www.youtube.com/watch? $\mathrm{v}=\mathrm{mLrsGegB} 43 \mathrm{I}$

${ }^{20}$ Vídeo disponível em: http://www.youtube.com/watch? $\mathrm{v}=\mathrm{zdmw} \ln \mathrm{SEa} 2 \mathrm{M}$

${ }^{21}$ Vídeo disponível em: http://www.youtube.com/watch?v=LUDOnaqziLo
} 
elementos teóricos da sua filosofia.

No terceiro momento da pesquisa, os alunos realizaram a leitura do capítulo XVII do Príncipe de Maquiavel, selecionando os conceitos sobre os quais o autor organiza seu pensamento político. Em seguida, cada aluno elaborou um mapa conceitual com os conceitos selecionados.

Após esta atividade cada aluno escreveu uma carta (mínimo 10 linhas) a um amigo da sala, a ser enviada juntamente com o mapa conceitual, explicando os conceitos utilizados. Em seguida responderam à carta recebida, comentando o seu conteúdo e os conceitos utilizados na construção do mapa conceitual. Na resposta poderiam concordar ou discordar, ou ainda, pedir esclarecimentos referentes aos conceitos de Maquiavel utilizados no mapa conceitual e na carta. $\mathrm{O}$ encerramento da atividade se deu com a leitura das cartas e suas respectivas respostas e considerações do professor sobre os conceitos utilizados na construção dos mapas conceituais sobre o que os alunos compreendiam por política e as novas compreensões decorrentes do estudo do capítulo XVII do Príncipe de Maquiavel.

No aspecto avaliativo, utilizamos a produção dos alunos - mapas e cartas - a fim de avaliar capacidade de argumentação. A avaliação ocorreu tendo como critério a compreensão dos conceitos filosóficos presentes no texto, possibilitando avançar metodologicamente na mobilização, problematização e investigação do conceito.

\section{Análise da produção dos alunos}

A vida cotidiana, conceito compreendido a partir de Agnes Heller (2008), pressupõe o ser humano na sua individualidade enquanto totalidade (sentimentos, ideias, intelectualidade...), esse ser é incompleto. Todavia, “o homem da cotidianidade é atuante e fruidor, ativo e receptivo, mas não tem nem tempo, nem possibilidade de se absorver inteiramente em nenhum desses aspectos; por isso, não pode aguça-los em toda sua intensidade" (HELLER, 2008.p.31).

A vida cotidiana no ser humano é dinâmica e diversa, pois consideram as relações socioeconômicas, o tempo e espaço do homem para a sua significação da realidade e constituição da sua individualidade e personalidade, visto que:

O homem nasce já inserido em sua cotidianidade. O amadurecimento do homem significa, em qualquer sociedade, que o indivíduo adquire todas as habilidades imprescindíveis para a vida cotidiana da sociedade (camada social) em questão. É adulto quem é capaz de viver por si mesmo a sua cotidianidade. (ibidem. p.33)

Esse aspecto ajuda a entender que o jovem que está aprendendo filosofia no ensino médio apresenta elementos sentimentais, ideias, paixões movidas também pela sociedade e cultura, que se encontram envolvidas. Quando, numa situação problema, ele pode se utilizar desse arcabouço para constituir uma perspectiva que resolva ou redirecione o problema, 
sabendo que a perspectiva filosófica não consiste no senso comum, mas, o pensar, pode apropriar-se desses elementos, bem como do pensamento realizado pelos filósofos para permitir ao indivíduo ferramentas conceituais para entender, analisar e agir numa conjuntura atual.

O professor de filosofia, quando reconhece o cotidiano do educando, abre a possibilidade de reconhecer o sujeito da aprendizagem, como elemento ativo do processo, fazendo com que a suas indagações não fiquem no senso comum, mas avancem no sentido de pensar de maneira rigorosa as problemáticas que envolvem seu ser no mundo.

Em que medida o uso de mapas conceituais, como técnica de mediação praxiológica para a leitura de textos filosóficos, poderia ser considerada também um mediação didática para o ensino da filosofia no nível médio?

Buscaremos evidenciar, por meio das produções dos alunos, os dois momentos fundamentais da pesquisa. Um que parte dos conhecimentos prévios dos alunos acerca de sua compreensão sobre o que é política, para, em seguida, analisar a compreensão dos alunos após a leitura do capítulo XVII d'O Príncipe, de Maquiavel.

Vamos à análise de dois mapas construídos pelos alunos, dentre os que compõem o “dossiê de aprendizagem" da turma, no qual alguns desses conceitos são representados:

Mapa 1:

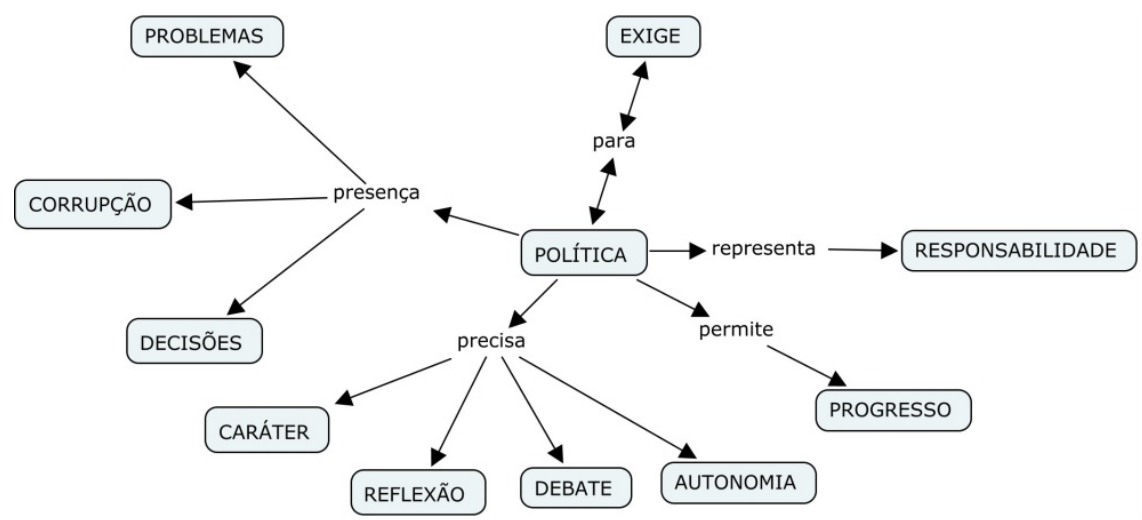

Mapa 2:

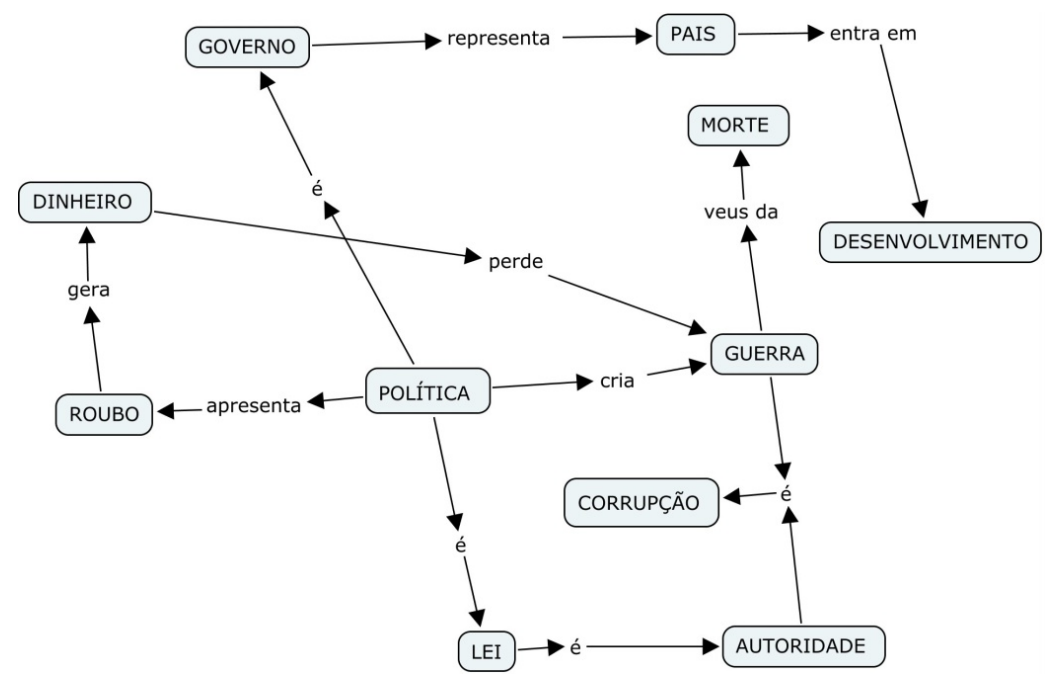


Foram produzidos 23 mapas pelos estudantes a partir dos dez conceitos prévios por eles selecionados. A análise dos mapas conceituais evidencia que os conceitos utilizados pelos alunos para conceituar política podem ser resultantes de estudos realizados durante seu processo de escolarização, da influência da mídia ou do seu cotidiano vivido, onde o tema surge aleatoriamente, mas está presente. Para efeitos de análise, os conceitos foram categorizados em três grupos distintos: "organização da sociedade", "ética e política" e "política negativa".

Os conceitos que associam a política com a categoria "organização da sociedade" são os seguintes: aprovação de leis, câmara dos deputados, eleições, presidente, governadores, vereadores, sociedade, direito, dever, povo, representação, ideias, parlamentares, partidos, legislação, comandar, poder, economia, mundo, educação, ditadura, liderança, melhorias, país, eleições, participação, voto, campanhas, eleitores, democracia, debate, comunismo, administrar, autoridade, população, impostos, benefícios, estudo, informação.

Os conceitos que associam a política com a categoria "ética e política" são os seguintes: progresso, desenvolvimento, censo crítico, responsabilidade, autonomia, reflexão, honestidade, valores, harmonia, bem, mal, qualidade de vida, moral, escolhas, julgamento, dilemas, determinação, justiça.

Os conceitos que associam a política com a categoria "política negativa" são os seguintes: roubo, prisão, laranjas, dinheiro, corrupção, problemas, mensalão, decepção, escândalos, injustiças, mentiras, interesses, desigualdades, exclusão, aquecimento global, morte, guerra.

Após produzir os mapas conceituais sobre os conceitos que elegeram para definir política, os alunos escreveram um texto dissertando sobre os conceitos que utilizam no mapa e explicitarem as relações conceituais. Os textos selecionados evidenciam a categorização acima, nos quais estão evidenciados alguns conhecimentos prévios trazidos pelos alunos, como, por exemplo, a necessidade da ética na política e os constantes escândalos envolvendo políticos eleitos.

A política começa de fato quando um candidato se candidata a qualquer cargo dentro da política. Os políticos vão disputar nossos votos mostrando suas propostas, e promessas, que sempre visam melhorias para a população ou município. Quando o candidato consegue se eleger ele, na maioria dos casos vai tentar cumprir com os principais elementos que compõe a política. (Jefferson $-3^{\circ}$ ano)

Depois de ter conquistado a confiança da população o então eleito busca propostas, também busca soluções. Também é seu papel exigir os direitos das pessoas e exercendo a cidadania, buscando a solução de todos os problemas. Como em todos os lugares do mundo, na política, sempre haverá os corruptos, que são a minoria, assim, gerando a famosa corrupção, levando a população a criar um preconceito a tudo relacionado a política. A corrupção existe, mas não são todos os políticos que a exercem, devemos parar com esse tipo de preconceito. (Melissa $-3^{\circ}$ ano).

Ao pensar o processo de "aprender significativamente implica atribuir significados e estes têm sempre componentes pessoais. Aprendizagem sem atribuição de significados 
pessoais, sem relação com o conhecimento preexistente, é mecânica, não significativa." (MOREIRA, 1997, p.5). Percebemos como o processo relacional do conhecimento estruturado graficamente no mapa conceitual é compartilhado, compreendido e analisado no coletivo da sala de aula, tendo como elemento inicial uma indagação que se reporta a elementos da realidade no caso $O$ que é política? Por utilizar-se de elementos do cotidiano, é importante a explanação para o coletivo e sua indagação sobre os conceitos para apurar o entendimento, sair do senso comum e entender de maneira rigorosa o sentido do conceito.

A partir da mediação feita pelo professor com a exibição do vídeo e comentários da obra O Príncipe, de Maquiavel, os estudantes reelaboraram os mapas conceituais, apresentados a seguir.

Mapa 01:

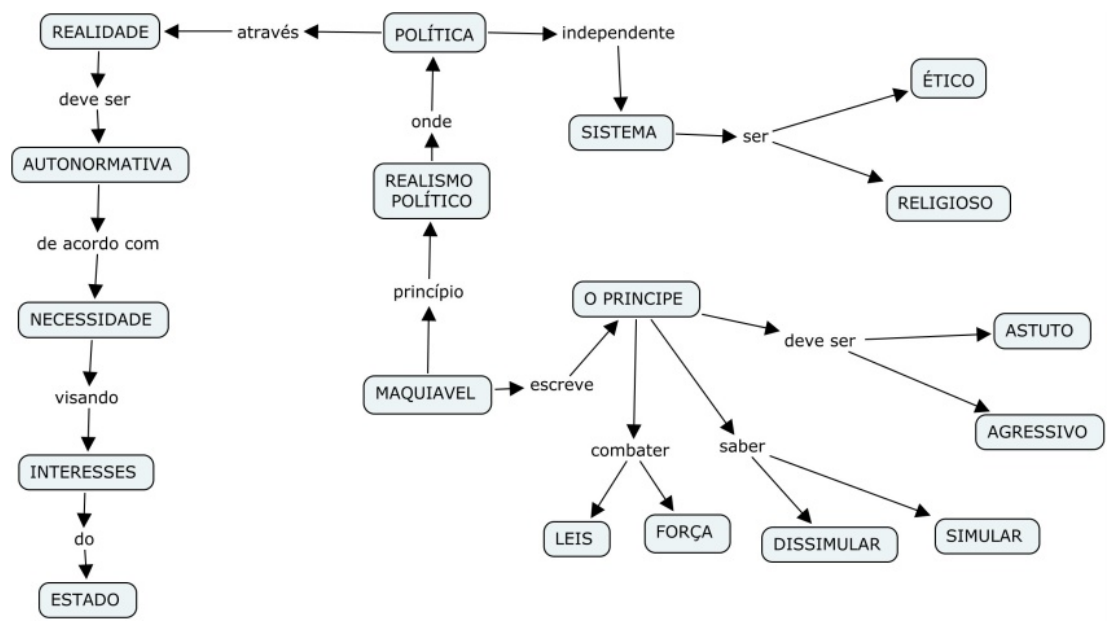

Cara amiga Pâmela.

Após ler atentamente o capítulo VXII da obra de Maquiavel devo apresentar-lhe as minhas singelas conclusões. A problemática de Maquiavel era: como chegar ao poder? Como exercê-lo? Como conservá-lo? Para isso ele parte de sua doutrina realista, onde a política constitui uma ciência autônoma e independente de qualquer sistema ético ou religioso. Príncipe não era necessariamente uma pessoa imoral ou cruel, mas visava, sobretudo, os interesses do Estado, não importando como alcançaria esses interesses. Ele, também deveria observar e estar atento às pessoas ao seu redor e seus súditos, sendo astuto (como a raposa) e agressivo (como o leão). Na política a aparência é tão importante quanto a substância: assim é preciso ser simulador e dissimulador, afinal os homens são tão ingênuos e sujeitos às necessidades do momento que aquele que engana encontrará sempre quem se deixe enganar. Portanto, Maquiavel expressa a preocupação exclusiva com a eficácia do poder político, com a competência do governante em exercer o poder, lançando mão de todos os meios a seu alcance. Para se obter os fins desejados não importando os meios utilizados.

Atenciosamente, Josane.

Querida amiga Josane

A princípio de suas conclusões pude observar que Maquiavel dizia que o príncipe poderia combater com a força e a lei, que ele poderia ser agressivo ou não, que as pessoas tinham o direito de ser independente. Que a política vai atrás da realidade para ver as necessidades e os interesses que o Estado tem de impor. Maquiavel se preocupa com o poder político, para conseguir seus objetivos desejados sem se preocupar com o que se utilizou.

Atenciosamente. Pâmela. 
A filosofia, quando reconhece o cotidiano do educando, permite reconhecer o sujeito da aprendizagem como elemento ativo do processo, fazendo com que suas indagações não fiquem no senso comum, mas que ele possa pensar de maneira rigorosa sobre as problemáticas que envolvem este ser no mundo. Como apresenta Horn sobre a mediação praxiológica, para a filosofia no universo do ensino médio onde o,

Filosofar com o cotidiano do aluno a partir da música, dos jornais, das poesias, enfim com o universo cultural do jovem, não significa abandonar nem perder de vista o texto filosófico - acadêmico -, mas ao contrário, por estas estratégias introduzi-lo conscientemente como referência para a reflexão filosófica. Não é necessário partir do texto filosófico, mas é preciso - de um jeito ou de outro chegar a ele. (HORN. 2009.p.97)

Percebemos que, após o trabalho com o capítulo XVII do Príncipe de Maquiavel, e a explanação dos mapas conceituais realizadas pelos alunos do texto, bem como as indagações feitas pelo coletivo na sala de aula, permitiram uma superação da visão inicial de política e das qualidades necessárias para o exercício do poder.

\section{Conclusão}

O ensino da filosofia no ensino médio pode utilizar vários instrumentos para mobilizar os alunos para esse processo. Segundo Obiols (2002. p.127), é fundamental que a aula de filosofia tenha como ponto de partida da vida cotidiana do educador, de sua prática social, respeitando o educando e compartilhando com este de seu interesse, fazendo com que os questionamentos produzam uma investigação significativa e não mecânica. A investigação por meio dos textos e da reflexão filosófica ao longo da sua tradição, leva ao questionamento e ao interesse investigativo oriundo da vida cotidiana.

Quando, mediados praxiológicamente pelo professor, os alunos elegem e defendem os conceitos e as ligações presentes no mapa aprendem que o conhecimento é dinâmico e o questionamento dos colegas não desmerece o trabalho realizado, e, sim, permite aos interlocutores aprofundar ou demonstrar o elemento que, por alguma condição, estava implícito e que a sua explicitação traga beneficio para o entendimento do ponto abordado.

\footnotetext{
Na medida em que os alunos utilizarem mapas conceituais para integrar, reconciliar e diferenciar conceitos, na medida em que usarem essa técnica para analisar artigos, textos capítulos de livros, romances, experimentos de laboratório, e outros materiais educativos do currículo, eles estarão usando o mapeamento conceitual como um recurso de aprendizagem. (MOREIRA, 2010, p.17)
}

A aprendizagem significativa pensada por David Ausubel pressupõe que o conhecimento para ser significativo deve se ligar a um conhecimento prévio, buscar uma âncora (saber tácito ou científico anteriormente adquirido) para que o novo conhecimento não 
seja meramente memorizado, para ser reproduzido num processo avaliativo e depois esquecido.

As análises iniciais desta pesquisa demonstram a importância da intencionalidade no processo de aprendizagem e que o conhecimento a ser apreendido deve ser significativo para o sujeito. As mediações da aprendizagem que contribuem para a realização deste processo são importantes. O mapa conceitual pode ser significativo no processo do filosofar com educandos do ensino médio, especialmente no que tange a representação gráfica do conhecimento possibilitando a investigação e análise individual e coletiva do problema filosófico como condição desenvolver o pensamento rigoroso, fazendo com que o processo do conhecimento possa ocorrer de maneira significativa ao educando.

Submetido em 18 de abril de 2013. Aprovado para publicação em 25 de julho de 2013.

\section{REFERENCIAS}

ARISTÓtElES. A Política. Trad. Nestor Silveira chaves. São Paulo: Escala, [s.d.].

. Órganon: Categorias, Da interpretação, Analíticos anteriores, Analíticos posteriores. Trad. Edson Bini. São Paulo: Edipro, 2005

ENGEL, I. G. Pesquisa-ação. Educar em Revista. Curitiba, n. 16, p. 181-191. 2000. Editora da UFPR

HELlER, Agnes. O Cotidiano e a História. Trad. Carlos Nelson Coutinho e Leandro Konder. São Paulo: Paz e Terra, 2008.

HORN, Geraldo Balduíno. Por uma mediação praxilógica do saber filosófico em sala de aula. In: Maria Auxiliadora Schmitd; Tania Maria Garcia Braga; Geraldo Balduino Horn. (Org.). Diálogos e perspectivas de investigação. Ijúi: UNIJUÍ, 2008, v. 01, p. 179-195.

HORN, Geraldo Balduíno. Por uma mediação praxiológica do saber filosófico no ensino médio: analise e proposição a partir da experiência paranaense. São Paulo: FEUSP, 2002.

LIBÂNEO, José Carlos. Pedagogia e pedagogos, para quê? $8^{\mathrm{a}}$ ed. São Paulo: Cortez, 2005. 
MAQUiAVEL, Nicolau. O Príncipe. Os Pensadores. Vol. 06. São Paulo: Nova Cultural, 1996.

MOREIRA, M. A. Mapas conceituais e aprendizagem significativa. São Paulo: Centauro, 2010.

NOVAK, J. D. Uma teoria da educação. São Paulo: Pioneira, 1981.

OBIOLS, Guillermo. Uma Introdução ao ensino da Filosofia. Trad. Sílvio Gallo. Ijuí: Unijuí, 2002.

SAVIANI, Nereida. Saber Escolar, currículo e didática: problemas da unidade conteúdo/método no processo pedagógico. $4^{\mathrm{a}}$ ed. Campinas: Autores Associados, 2003.

TAVARES, Romero. Construindo mapas conceituais. Ciências \& Cognição; Ano 04, Vol. 12. 2007, pp. 72-85. Disponível em: www.cienciasecognicao.org

WUENSCH, A.M. Por uma Didática da Filosofia. In: SARDI, Sérgio Augusto; SOUZA, D. G.; CARBONARA, Vanderlei. (Org.). Filosofia e Sociedade: Perspectiva para o Ensino da Filosofia. Ijuí: Unijuí, 2007. 